Published in Proceedings of the 1999 IEEE/ASME Joint Railroad Conference, April 1315, 1999, IEEE Catalog Number 99CH36340, ASME RTD Volume 16

\title{
INVESTIGATION AND SIMULATION OF LATERAL BUCKLING IN TRAINS
}

\author{
Ronald Mayville, Robert Rancatore, Lisa Tegeler \\ Arthur D. Little, Inc. \\ Cambridge, Massachusetts 02140
}

\begin{abstract}
One of the philosophies of crash energy management for passenger trains is to ensure that the vehicles remain in line during a collision so that the crush zones are fully utilized and impacts with wayside objects is prevented. Our work to develop methods of resisting lateral buckling of trains has led to a thorough study of the conditions under which it occurs. In this paper we present a review of accidents to show when buckling occurs in practice for passenger trains. The bulk of the work to be presented is based on the application of a collision dynamics computer model that incorporates several important train and track parameters, including: track/train interaction; derailment; three-dimensional motion of the vehicles (including yaw, pitch and roll); curved motion; coupler/bellmouth interaction; and end crush of the vehicles. The analysis is carried out to study the effects of number of vehicles, track curvature, and collision speed. The results show that lateral buckling is quite difficult to induce unless there are many vehicles (over about 8-10) in the case of a head-on or rear-end collision with another train, or that the train can continue moving for some distance after, say, impacting a relatively light object in a grade crossing. We also present a method to prevent or minimize lateral buckling in passenger trains and apply the computer model to assess its effectiveness.
\end{abstract}

\section{INTRODUCTION}

Protection of train occupants during a collision requires that the collision energy be dissipated in a controlled manner with limited crush and that secondary collisions, those between the rail vehicles and other wayside objects and between the passengers and the interior, be minimized. These objectives are largely achieved with the use of vehicle end crush zones, strengthened occupant spaces and the prevention of override and lateral buckling.

Override is the occurrence of one rail vehicle climbing over the underframe of another rail vehicle. It is a particularly dangerous collision mode because it can lead to substantial crush of the generally weaker superstructure that encloses the operator and passenger spaces. Lateral buckling refers to the derailment at a coupled interface between two rail vehicles and the subsequent, sometimes large, lateral deflections away from the track. The occurrence of this collision mode can lead to impact with another object and prevent crush zones from operating properly.

This paper is based on a study of override and lateral buckling of passenger vehicles [1] and provides a description and analysis of the buckling phenomenon and analytical structural concepts to prevent and protect against lateral buckling. The subject of colliding and coupled car override is outside the scope of this paper.

\section{LATERAL BUCKLING MODES}

Lateral buckling refers to the derailment and substantial sideways motion of a train at one or more coupled interfaces. This mode, though not as dangerous as override, can lead to uncontrolled motions of the rail vehicles, such as roll-over, and collisions with other wayside objects, including other trains and bridge abutments. Figures 1 and 2 are example photos from passenger train accidents in which lateral buckling occurred.

There are two types of lateral buckling we have encountered in our review of accidents. The first type, predominant in Figure 1, is referred to as the saw-tooth mode, and occurs when the coupled ends of two rail vehicles move laterally with respect to each other until contact is made between the vehicle bodies (rather than just through the couplers.) Figures $3 \mathrm{a}$ and $3 \mathrm{~b}$ show schematically the vehicle end orientations before and after saw-tooth buckling occurs. Our observations and modeling results suggest that this is a common phenomenon in collisions involving passenger trains. 


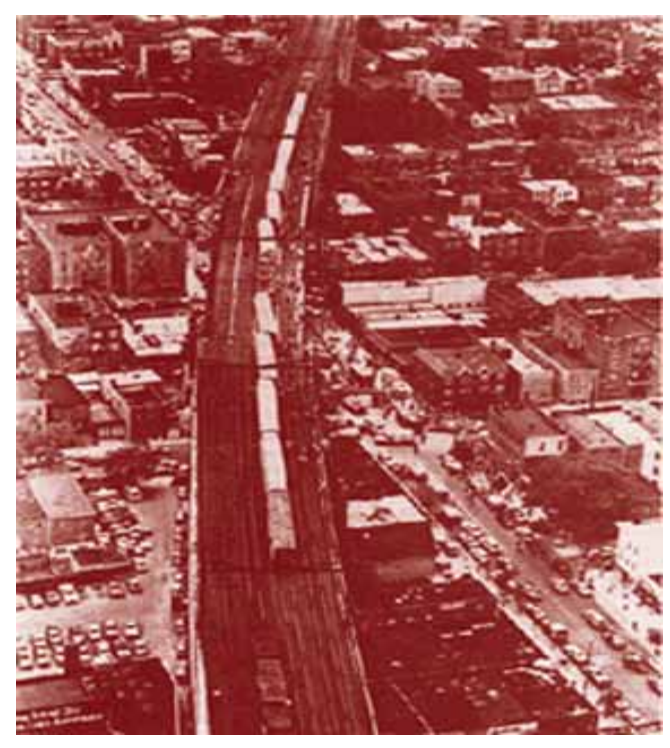

Figure 1. Example of Saw-tooth Buckling (Queens, NY, 1984) [2]

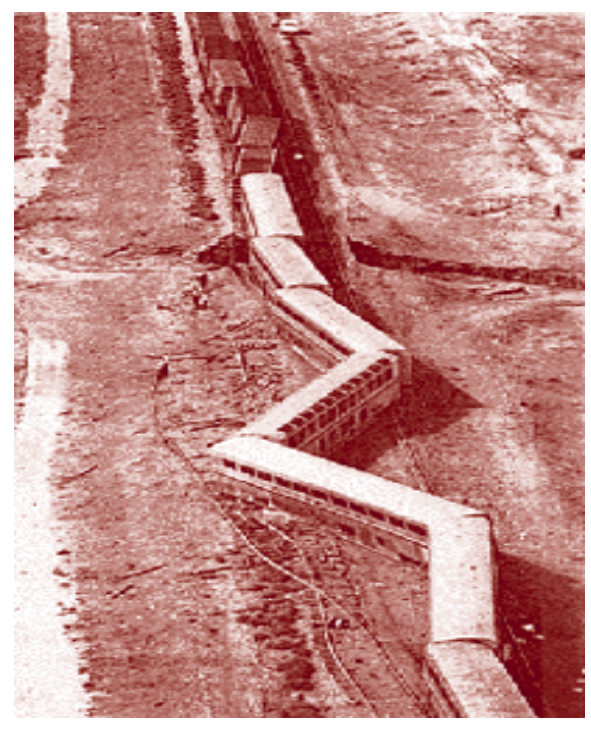

Figure 2. Example of Large Displacement Lateral Buckling (Kingman, AZ, 1997) [3]

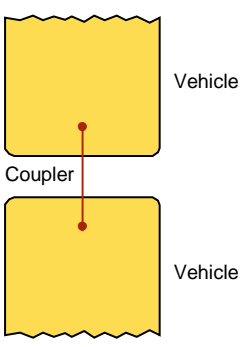

(a)

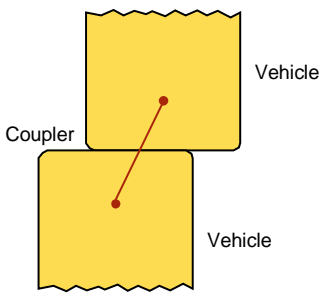

(b)
Figure 3. Schematic of Saw-tooth Buckling

We have also carried out calculations which indicate that the relatively frequent occurrence of the saw-tooth mode in passenger train collisions is the primary reason coupled car override rarely occurs. In this case, the underframes of the vehicles interact directly, with little vertical displacement difference, making it difficult for ramp formation, one of the modes of coupled car override, to occur.

The second type of buckling, and the one we are most concerned with preventing, is the large lateral deviation from the track such as that shown in the photo in Figure 2. We have found no accidents in which this type of buckling occurs in a collision between a passenger train and another train. Rather, we find instances of this type of buckling only in derailments of passenger trains which might, for example, occur because of a perturbation in the track, or in trainto-train collisions involving very long trains such those used in freight transportation. For example, Figure 2 corresponds to an accident in which the train derailed after passing over a partially washed-out bridge. Our modeling results support these accident observations. Note that a large lateral buckle would have been quite dangerous on the elevated track depicted in Figure 1.

Although not specific to this study, we are also interested in preventing lateral buckling so that collision energies can be absorbed in the deformation of crush zone-containing rail vehicle ends, rather than in uncontrolled motions (residual kinetic energy) of the vehicles. The technique of dissipating collision energy in a controlled manner is used in crash energy management and is the focus of a separate paper [4]. 


\section{TRAIN MODEL}

An analysis and assessment of the conditions associated with lateral buckling requires a full three-dimensional collision dynamics model. A significant part of the overall project whose results are described here required the development of such a model. Many of our calculations were then conducted using a single train configuration traveling on a segment of tangent track that transitions into curved track.

We conducted our analyses of lateral buckling using the commercially available dynamics modeling program, ADAMS [5]. The model developed includes several important features shown in Figures 4 and 5. The typical vehicle is made up of a body, two trucks and front and rear sill elements and front and rear coupler elements. Figure 4 depicts a typical modeled vehicle. Properties of the elements in the model, such as mass and moments of inertia, are assigned to each element. The elements are connected by joints and forces allowing specific degrees of freedom or constraints, as needed. The crushable elements, such as the sill, are represented by nonlinear force/crush curves developed from finite element analyses of the vehicle structure.

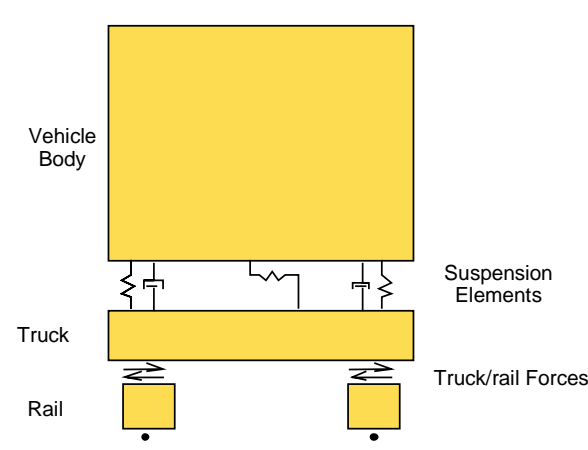

Figure 5. Schematic of Suspension and Truck/Rail Interaction

\section{SAW-TOOTH LATERAL BUCKLING}

Figure 6 shows the simulated generation of the saw-tooth mode of lateral buckling for a threecar consist colliding with a rigid surface in a $2.6^{\circ}$ curve.

The relative lateral displacement between ends at a coupled interface that has experienced the sawtooth mode is approximately 2 to $3 \mathrm{ft}$, indicating that at least one of the vehicle ends must derail. The predicted results compare quite favorably to observations, as indicated by the photographs of passenger train accidents in Figures 1 and 2. The model prediction were also found to be relatively insensitive to the derailment criterion used.

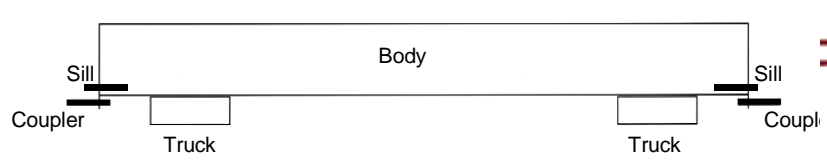

Figure 4. Typical Modeled Vehicle

The vehicle body is permitted to pitch, yaw and roll as well as to translate in all three directions. The trucks are attached to the track segments via friction elements which keep the vehicle on the track during normal curving but permit a derailment to occur when the friction force is overcome during a collision. The coupler element also has pitch, yaw and longitudinal translation degrees of freedom and is constrained against these motions by springs representing either the bellmouth structure or the deformation and crush resistance of the draft gear and underframe. Figure 5 schematically shows the modeling of the suspension and truck/rail forces.
Figure 6. Simulated Saw-tooth Buckling Mode

Our collision dynamics calculations indicate that the occurrence of this saw-tooth mode in collisions requires a relatively small lateral perturbation. Several calculations were carried out in which the first car was permitted to enter a $2.6^{\circ}$ curve by various amounts before colliding with a rigid surface. For example, when the lead vehicle strikes a rigid surface that is placed $40 \mathrm{ft}$ into the curve, the corresponding lateral displacement of the front end of the vehicle from the projection of the tangent track is 4.3 inches. We found that a lateral displacement of the front end of the colliding train as small as 3 inches was sufficient to induce the saw-tooth mode of lateral buckling (see Figure 7.) Such small lateral displacements of one end of a vehicle body relative to another are not difficult to induce in 
normal operation. This explains why the creation of the saw-tooth mode is so common in passenger train collisions.

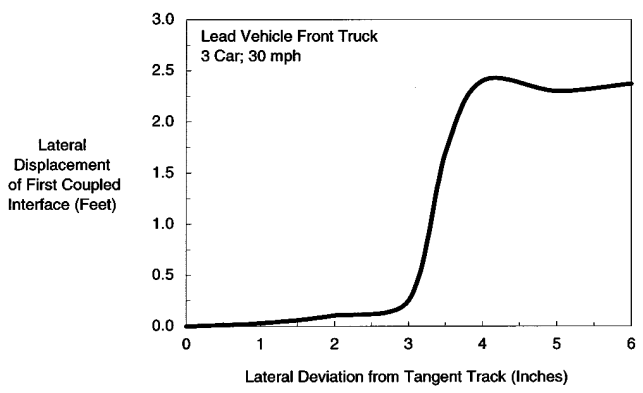

Figure 7. Lateral Deviation Required to Initiate Saw-tooth Mode

Analyses in which the saw-tooth mode is induced also explain why coupled car override is rare. Figure 8 shows a plot of the pitch motion of one vehicle at the first coupled interface of a simulated passenger train collision for two conditions: (1) a case in which the saw-tooth mode is prohibited; and (2) a case in which the saw-tooth mode occurs. The results show that when the saw-tooth mode is prohibited, the coupled vehicle ends show substantial pitch of the type that can lead to catapulting, coupler fracture and override. When the saw-tooth mode occurs, there is very little relative pitch but significant yaw.

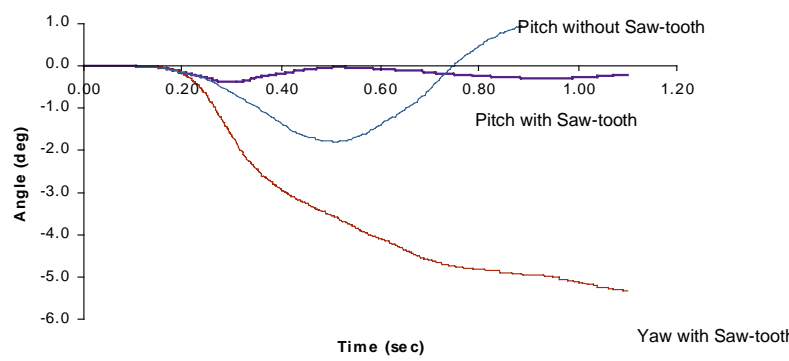

Figure 8. Pitch and Yaw of First Coach in Commuter Train

\section{LARGE DISPLACEMENT LATERAL BUCKLING}

If the collision energy is sufficient, the saw-tooth mode will develop into a mode of substantially larger lateral buckling. Figure 9 shows the final configuration of several cars in a simulated nine vehicle passenger train that has collided at 50 mph with a rigid surface in a $2.6^{\circ}$ curve. The lateral displacement of the first coupled interface is approximately $13 \mathrm{ft}$ in this figure. Such large displacements pose the risk of the rail vehicle colliding with another object.

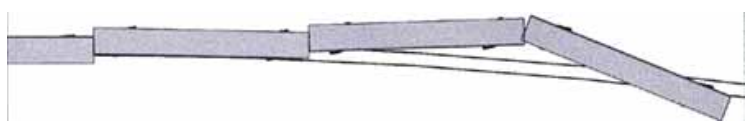

Figure 9. Simulated Large Lateral Buckling

Several collision dynamics analyses were carried out to investigate the conditions under which the larger mode of lateral buckling would occur. These are shown in Figures 10-12. Figure 10 shows the effect of the number of vehicles in the consist on lateral buckling displacement for a 30 mph collision into a rigid barrier on a $2.6^{\circ}$ curve. This result indicates that, for many commuter trains, which generally consist of six vehicles or fewer, large displacement lateral buckling would not be expected in collisions with other similar trains. On the other hand, large displacement lateral buckling appears possible for longer trains, such as those found in intercity passenger and freight service.

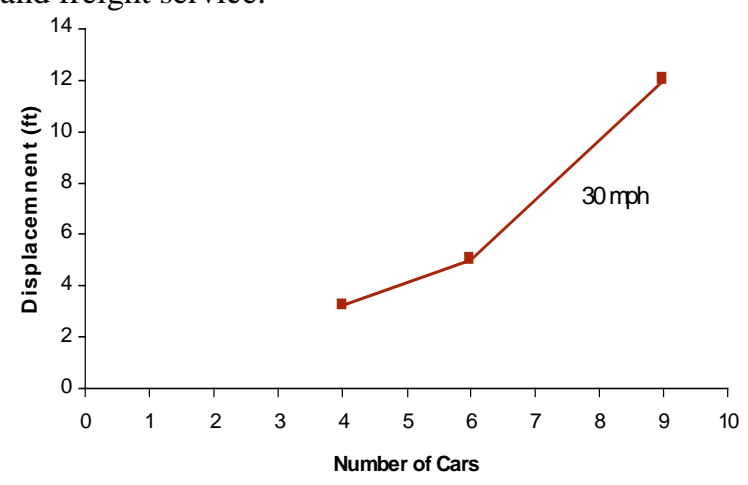

Figure 10. Buckling Displacement versus Consist Length

Figure 11 shows a plot of lateral displacement as a function of collision speed for three train sizes in a $2.6^{\circ}$ curve. The fact that the displacement does not increase substantially with speed for the smaller consists is a result of the collision energy being dissipated in crush rather than lateral movement. 


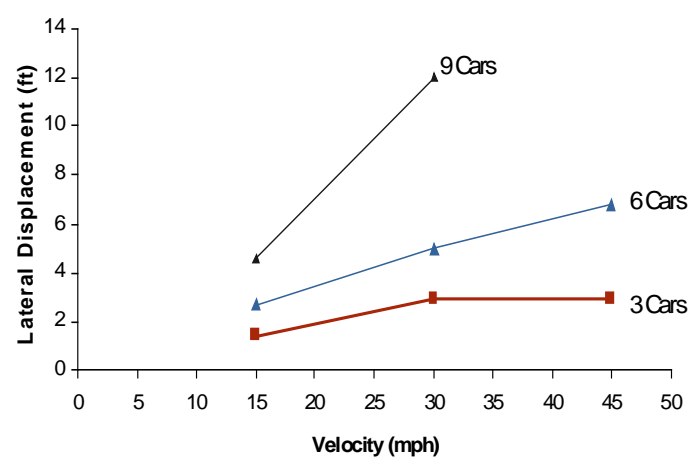

Figure 11. Lateral Displacement versus Consist Velocity

Finally, Figure 12 shows a plot of lateral displacement as a function of track curvature for a six vehicle consist colliding with a rigid barrier at $30 \mathrm{mph}$. As expected, track curvature has a marked effect on lateral buckling movement.

The above discussion suggests that large displacement lateral buckling in collisions between similar trains is only a concern with long passenger trains. Furthermore, such a collision mode only appears possible when there is an initial, relatively large lateral perturbation arising from, for example, the lead vehicles being in a curve or switch or having derailed for some reason.

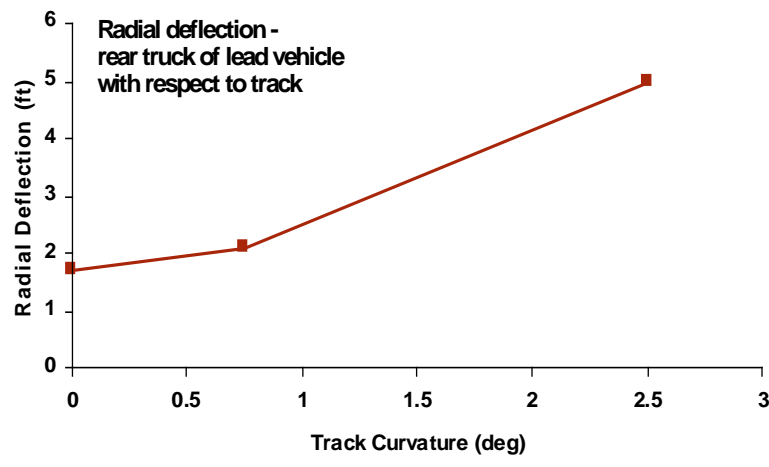

Figure 12. Radial Deflection versus Track Curvature

\section{PREVENTION STRATEGY}

In order to prevent large lateral displacements in these situations, it appears necessary to have some type of moment resistance (about a vertical axis) at the coupled interfaces. Ideally, this moment resistance would act only in the event of a collision, so that there would be no interference with normal curving operations. The degree of moment resistance will naturally depend on the curvature and speed during the collision.

Figure 13 shows the lateral displacements predicted from collision dynamics calculations in which a moment is allowed to be generated in the coupled interfaces only after the collision occurs. The track curvature in this case is again $2.6^{\circ}$, there are nine vehicles in the consist, and the collision speed is $30 \mathrm{mph}$. This figure shows that a substantial moment resistance is required if the lateral displacements are to be kept low. For example, a moment resistance of 3,000 ft-kips limits the lateral displacement to about $3 \mathrm{ft}$ for the conditions simulated.

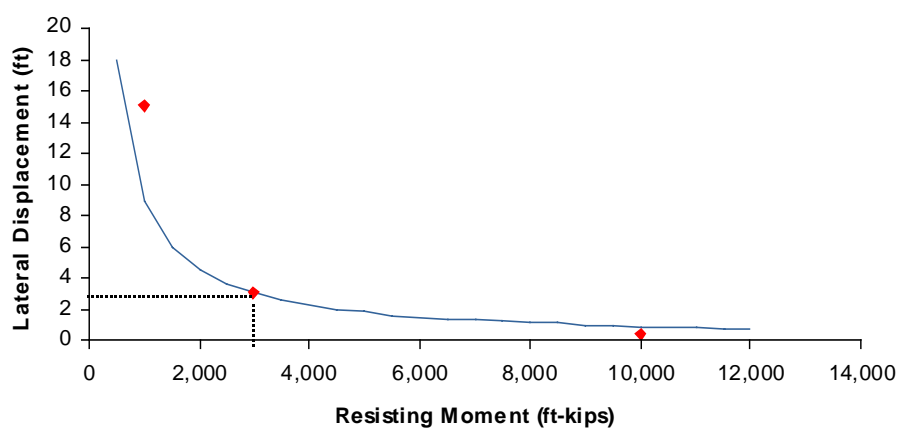

Figure 13. Reduction in Lateral Buckling as a Function of Resisting Moment.

\section{SUMMARY AND CONCLUSIONS}

Collision dynamics analyses and review of accidents revealed how the common occurrence of saw-tooth lateral buckling in passenger train collisions makes coupled car override rare.

Computer simulations also demonstrated that large displacement lateral buckling appears to 3 only be possible in train-to-train collisions when the consist is long, say 9-10 vehicles or more. However, in derailments, in which little energy is initially absorbed in vehicle crush, such a mode can occur with fewer vehicles. A large moment resistance, on the order of $3000 \mathrm{ft}$-kips at the coupled interface is necessary to prevent large lateral buckling.

An important result that has come from our work is that high collision loads promote lateral buckling. Such high loads are determined by the strength of the rail vehicle end components, including the coupler hardware and the 
underframe. Thus, our analyses indicate that vehicles that include crush zones at their ends, for which the peak loads are initially lower, are less prone to exhibit lateral buckling.

\section{ACKNOWLEDGEMENTS}

This effort was conducted under contract to the Volpe National Transportation Systems Center, as part of the Equipment Safety Research Program sponsored by the Office of Research and Development of the Federal Railroad Administration. The authors would like to thank Mr. David Tyrell, the Volpe Center Technical Monitor, for his helpful insight and direction.

\section{REFERENCES}

1. Mayville, Rancatore, Stringfellow, "Approaches to Preventing Override and Lateral Buckling in Passenger Trains", Report to the Volpe National Transportation Systems Center under Contract DTRS-5793-D-00026, Cambridge, MA (1999)

2. NTSB Report RAR-85-09 "Head on Collision of National Railroad Passenger Corporation (Amtrak) Passenger Trains Nos 151 and 168, Astoria, Queens, New York, NY, July23, 1984"

3. NTSB Report RAR-98-03 "Railroad Accident Report Derailment of Amtrak Train 4, Southwest Chief, on the Burlington Northern Santa Fe Railway near Kingman, Arizona, August 9, 1997"

4. Mayville, Stringfellow, Rancatore, "Development of a Passenger Rail Vehicle Crush Zone", IEEE/ASME Joint Railroad Conference, 1999

5. ADAMS, Mechanical Dynamics, Inc., Ann Arbor, Michigan 